Brit. Heart F., 1968, 30, 141.

\title{
Situs Inversus with Cor Triloculare Biatriatum and a Single Arterial Trunk
}

\author{
J. P. P. STOCK^ AND C. GILES \\ From the North Staffordshire Hospital Group
}

Cor triloculare biatriatum with a single arterial trunk is a rare malformation of the heart, usually incompatible with survival for more than a few days. Wilson (1798) was probably the first to report an example.

\section{Case Report}

The patient, a woman aged 22, was referred to one of us (J.P.P.S.) from the antenatal clinic. She was a primigravida estimated to be six months pregnant. She gave a history of cyanosis since birth. Following an intravenous angiocardiogram at another centre, a diagnosis of situs inversus with Fallot's tetralogy had been made at the age of 10 . A right-sided Blalock operation had been carried out, anastomosing the right subclavian artery to a right-sided pulmonary artery. Following operation, she was greatly improved symptomatically, with reduction in central cyanosis and a greatly increased capacity for effort. Since her operation she had had two emergency admissions to hospital on account of haemoptysis. On each occasion, the radiologist had reported inflammatory shadowing in the right upper zone. She denied any increase in symptoms since becoming pregnant and only admitted to moderate effort dyspnoea.

On clinical examination, there was deep central cyanosis and clubbing of the fingers. Her peripheral pulses were normal and her jugular venous pulse was raised about $1.5 \mathrm{~cm}$. above the sternal angle. The apex beat was thrusting in quality and felt in the fifth right intercostal space, just beyond the mid-clavicular line. On auscultation, there was a loud presystolic gallop audible at the apex, but no bruits were detected over the praecordium. A continuous machinery murmur was audible posteriorly, to the right of the mid-line, in the interscapular region. Her cardiograph showed the characteristic changes of dextrocardia in the limb leads: the conventional praecordial leads were compatible with grade IV right ventricular hypertrophy. Her haemoglobin was $20.5 \mathrm{~g} . / 100 \mathrm{ml}$. Three weeks later, when approximately $7 \frac{1}{2}$ months pregnant, she went into premature

* Address: City General Hospital, Newcastle Road, Stokeon-Trent. labour and was uneventfully delivered of a stillborn foetus.

When reviewed in the cardiac follow-up clinic one month later, there was no change in her symptoms or physical signs. She was reviewed once again, three months later, when the physical signs in her heart were unchanged, but it was noted that the machinery murmur due to her Blalock operation was no longer audible. One week later she died suddenly while out shopping.

Necropsy. Internal examination revealed situs inversus totalis of the thoracic and abdominal viscera. The right pleural sac contained about $1300 \mathrm{ml}$. of partially clotted blood and several old fibrous adhesions.

The heart was approximately one and a half times the normal in size. It was a cor triloculare consisting of two inverted atria which opened by two normal atrioventricular valves into a single ventricle. There was a normal bicuspid mitral valve on the right and a normal tricuspid valve on the left. The single ventricle was thick-walled, the cut surface measuring $2 \mathrm{~cm}$., with no evidence of an interventricular septum (Fig. 1 and 2). A single arterial trunk arose from its base with a normal tricuspid aortic valve and a normal origin of the two main coronary arteries. The thoracic viscera were preserved in toto so the individual weights of the heart and lungs could not be recorded. Two small defects were present in the atrial septum. The single arterial trunk gave off the innominate, right common carotid, and right subclavian arteries, in that order, from its arch which was right-sided (Fig. 3 and 4). Just beyond the arch, there was a thimble-shaped depression of the internal dorsal wall approximately $2 \mathrm{~cm}$. in diameter and $1.5 \mathrm{~cm}$. in depth. From the right side of this depression an artery with a stenosed orifice was found going into the right lung. After some search, a vestigial artery was found connecting the left side of this depression with the left lung. The right-sided "pulmonary" artery and the right subclavian artery both communicated with a thick-walled aneurysm, $5 \mathrm{~cm}$. in diameter, which lay in the substance of the upper lobe of the (bilobed) right lung. There were a few atheromatous plaques in the intimal lining of the aneurysm which had ruptured 141 


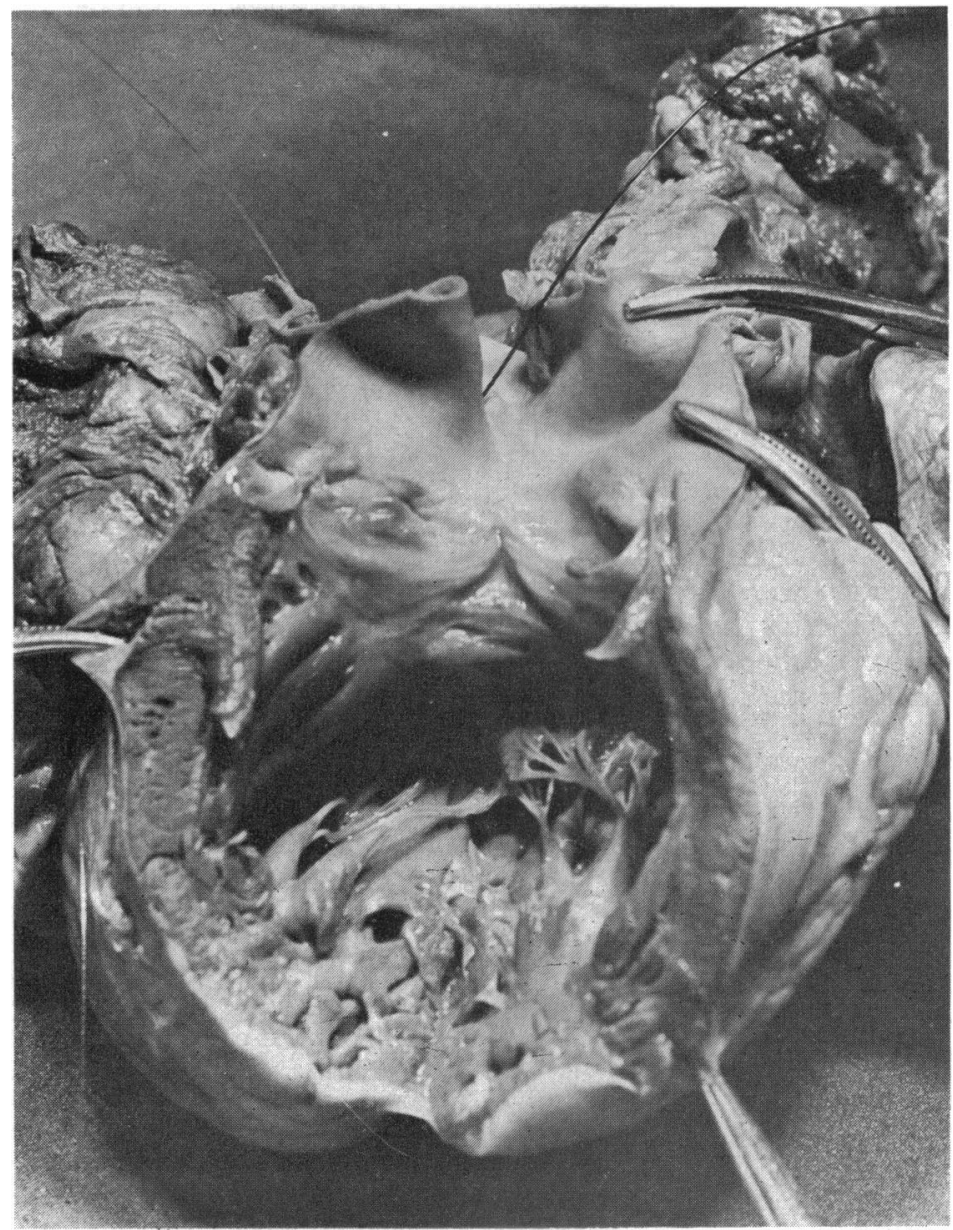

FIG. 1.-Photograph of common ventricle and semilunar valve of persistent truncus with coronary ostia.

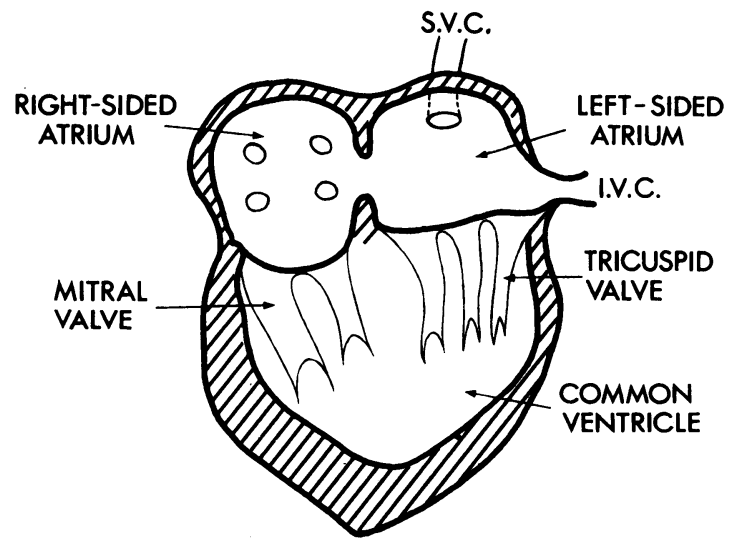

FIG. 2.-Diagram of heart. pleural cavity. There was extensive haemorrhage into the surrounding lung substance.

The inverted abdominal viscera were normal with no evidence of chronic heart failure. A normal spleen was present.

\section{Discussion}

The association of a single ventricle with a persistent truncus arteriosus is a rare anomaly. A common ventricle is most often associated with transposition of the great vessels. Elliott, Anderson, and Edwards (1964) found 30 examples among 800 cases of congenital heart disease. Of these, 26 showed transposition of the great vessels; in the remaining 4 without transposition, pulmonary stenosis was present. There was no example of a single ventricle with a single arterial trunk. It is tempting to regard 


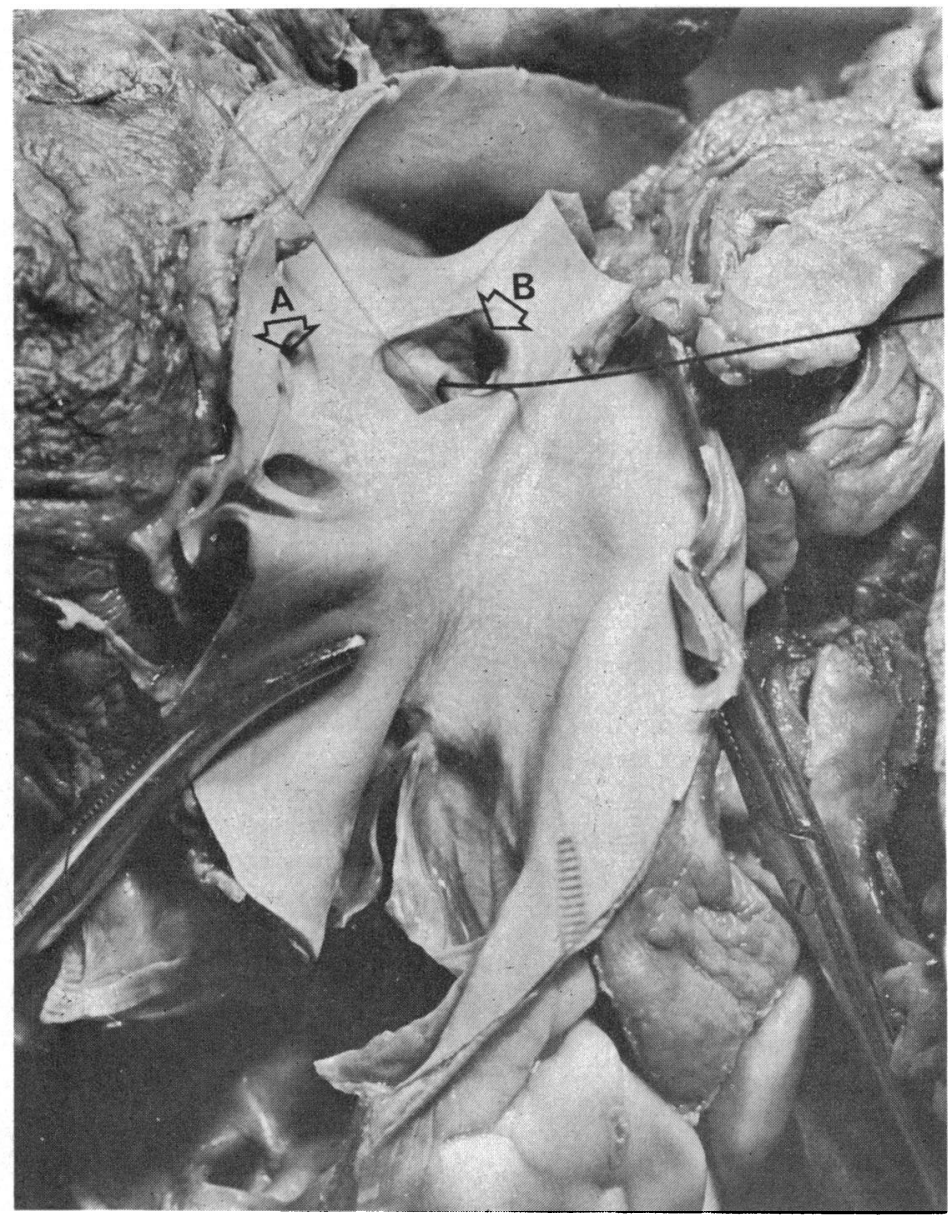

Fig. 3.-Photograph of persistent truncus. The arrow at $A$ points to the ostium of the right subclavian artery; the arrow at $B$ points to the common ostium from which arise the artery to the right lung (black thread) and also the vestigial artery to the left lung, which is not visible in the photograph.

the combination of a single ventricle with a persistent truncus as representing simultaneous failure in the development of the ventricular and bulbo-truncal septa. However, by no means all reported cases of a single ventricle with a single arterial trunk can be explained in this way. Siddoway and Chernish (1952) described 3 cases of their own and reviewed 25 cases reported as a single ventricle with a persistent truncus. After discussing the anatomical criteria for the diagnosis of persistent truncus, they rejected their own 3 and 22 of the reported cases, thus accepting only 3, namely those of Wenner (1909), Shapiro (1930), and Mehta and Hewlett (1945). Humphreys (1932) laid down 8 criteria for the diagnosis of persistent truncus, but these have now been reduced to 2 (Taussig, 1947; Collett and Edwards, 1949; and MacGilpin, 1950). The two criteria are: (1) only a single, large, arterial trunk should leave the heart without evidence of a second atretic vessel, and (2) this single vessel must give

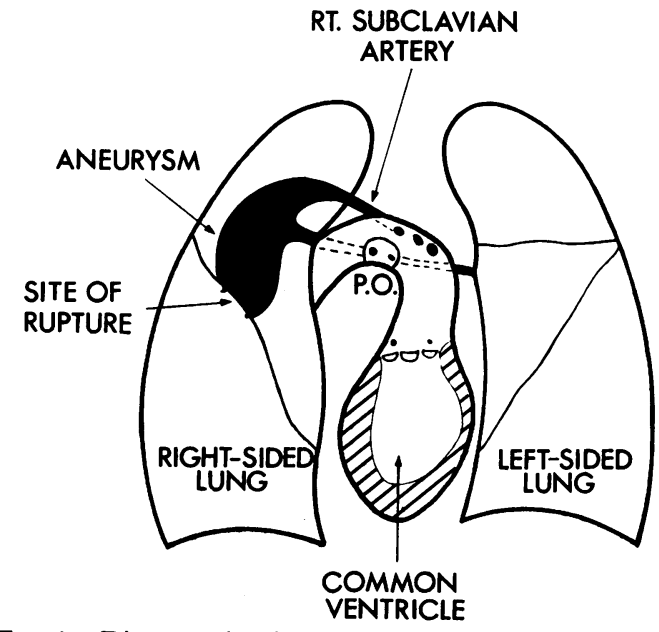

FIG. 4.-Diagram showing heart, lungs, and main vessels; also the pulmonary aneurysm at the site of the old Blalock operation. P.O.= ostium giving off arteries to both lungs. 
rise to both the systemic and pulmonary circulations and the coronary arteries must arise from its base. Although Humphreys stated that the valve between the truncus and ventricle should have 4 cusps, Collett and Edwards consider this to be variable and that a tricuspid valve is more usual. The presence of a "true" truncus implies that the bulbo-truncal ridges failed to develop and divide the primitive truncus into aorta and pulmonary artery. Siddoway and Chernish (1952) rejected 21 of the 25 published cases which were claimed to be examples of a single ventricle with a persistent truncus on the grounds that the single arterial trunk did not fulfil the two criteria of a "true" truncus. They suggested that in most of the cases the single arterial trunk was a solitary pulmonary artery since it did not give rise to the coronary arteries. In their view, the commonest cause of a single ventricle with a single arterial trunk was atresia or aplasia of the mitral valve. In consequence, the left ventricle and aorta were bypassed and failed to develop, the blood passing from the left atrium through an atrial septal defect into the right side of the heart. The single arterial trunk in these cases is therefore the pulmonary artery and the coronary arteries do not arise from its base. A second small vessel is usually demonstrable, supplying the coronary circulation, and this represents the atretic aorta. A careful search will usually reveal a rudimentary second ventricle in the muscular wall of the "single" ventricle.

Much less commonly, the single arterial trunk in association with a single ventricle is the aorta. This may be identified by a normal origin of the coronary arteries and the presence of an atretic pulmonary artery. The blood supply to the lungs in these cases is commonly via a ductus arteriosus. If mitral valve atresia is present as the primary cause, transposition of the great vessels must be assumed.

We suggest that our case is a "true" common ventricle with a "true" persistent truncus. Both $A V$ valves are present (though inverted) and there is no evidence of a second rudimentary ventricle or atretic main vessel. The single arterial trunk gives rise to normal coronary arteries and systemic vessels, and the arterial supply to the lungs arises just beyond the aortic arch. According to the classification of Collett and Edwards (1949), this is a type IV persistent truncus and presumably the sixth aortic arches failed to develop.

The artery to the left lung was atretic and could have carried little blood. The vessel to the right lung was larger, but its orifice was stenosed and this explains the beneficial result of the Blalock anastomosis.
To the best of our knowledge, aneurysm formation at the site of a Blalock operation with fatal rupture has not been previously described.

\section{Summary}

A case of situs inversus totalis associated with cor triloculare biatriatum and a persistent truncus is described.

Considerable functional improvement had followed a right-sided Blalock operation at the age of 10. At the age of 22, when $7 \frac{1}{2}$ months pregnant, she was uneventfully delivered of a stillborn foetus. Four months later she died suddenly. Necropsy revealed death to have been caused by rupture of an aneurysm in the right lung at the site of the Blalock anastomosis.

The single ventricle showed no evidence of a septum, but both atrioventricular valves were normal. There was no evidence of a second vestigial ventricle. The single arterial trunk gave origin to normal coronary arteries from its base. The aortic arch was right-sided and the main systemic vessels, though inverted, were normal. The arterial supply to the lungs arose from the aorta just beyond the arch. The artery to the left lung was vestigial and that to the right was stenosed at its orifice.

It is considered that this was a "true" truncus belonging to type IV of Collett and Edwards.

\section{References}

Collett, R. W., and Edwards, J. E. (1949). Persistent truncus arteriosus, a classification according to anatomic types. Surg. Clin. N. Amer., 29, 1245.

Elliott, L. P., Anderson, R. C., and Edwards, J. E. (1964). The common cardiac ventricle with transposition of the great vessels. Brit. Heart f., 26, 289.

Humphreys, E. M. (1932). Truncus arteriosus communis persistens. Criteria for identification of common arterial trunk, with report of a case with four semilunar cusps. Arch. Path., 14, 671.

MacGilpin, H. H., Jr. (1950). Truncus arteriosus communis persistens. Amer. Heart f., 39, 615

Mehta, J. B., and Hewlett, R. F. L. (1945). · Cor triloculare biauriculare; an unusual adult heart. Brit. Heart. F., 7, 41.

Shapiro, P. F. (1930). Detorsion defects in congenital cardiac anomalies: report of 3 cases with analysis of mechanism of their formation. Arch. Path., 9, 54.

Siddoway, J. L., Jr., and Chernish, S. M. (1952). Truncus arteriosus with a single ventricle. Amer. f. Dis. Child., 84, 706.

Taussig, H. B. (1947). Clinical and pathological findings in cases of truncus arteriosus in infancy. Amer. F. Med., $2,26$.

Wenner, O. (1909). Beitrage zur Lehre der Herzmissbilungen. Virchows Arch. path. Anat., 196, 127.

Wilson, J. (1798). A description of a very unusual formation of the human heart. Phil. Trans., 88, 346; also (1909). ibid. (abridged ed.), 18, 332. 